\title{
Além da racionalidade: em busca de um conceito mais amplo do processo deliberativo
}

Ana Carolina Ogando*

"As complexas sociedades democráticas modernas, desde a Segunda Guerra Mundial, enfrentam o dever de assegurar três bens públicos. São eles legitimidade, bem-estar econômico e um senso viável de identidade coletiva."

Seyla Benhabib

"Os indivíduos não podem 'estar situados' no mundo do outro e adotar sua 'visão de mundo' e nem deveriam tentar fazê-lo. Não obstante, eles podem comunicar-se além da distância e de suas diferenças. A voz cruza fronteiras, mesmo quando as respeita."

Nancy Love ${ }^{1}$

\section{Resumo}

Diante da ampliação das contemporâneas lutas pelo reconhecimento, em um contexto de maior visibilidade de novos atores nos espaços públicos, podem-se identificar as limitações do modelo liberal de democracia que enfatiza, sobretudo, a legitimidade, o poder e a racionalidade. Este artigo propõe-se a retomar as diversas críticas à democracia deliberativa, particularmente no que respeita ao uso da racionalidade como única forma de

* Doutoranda em Ciência Política pela Universidade Federal de Minas Gerais e pesquisadora do Núcleo de Estudos e Pesquisa sobre a Mulher (NEPEM) da mesma instituição. Endereço eletrônico: anacarolinaogando@gmail.com.

1 Citado por Iris Young, 1997, p. 50. Nancy Love, em "Politics and Voice(s): An Empowerment Knowledge Regime” (1991), sugere que a questão da compreensão (understanding) deveria ser entendida como um estado de ser com o outro e não o estado de estar no lugar/posição do outro. 
argumentação e de ação. A crítica ao uso da racionalidade será ancorada nas discussões feitas por Young $(1990,1997,2001)$ e por Hoggett e Thompson (2002). A incorporação de outras formas de ação e padrões comunicativos assinala uma tentativa de possibilitar maior inclusão nos processos deliberativos para que eles se tornem espaços de igualdade e emancipação.

Palavras-chave: Democracia deliberativa, racionalidade, inclusão.

\section{Introdução}

Nas últimas décadas, a visibilidade de novas subjetividades e novos atores teve forte e significante impacto tanto para a constituição de esferas públicas mais formais, quanto para os novos espaços públicos. Um dos traços mais notáveis desse processo está ligado ao fato de que a amplificação das pressões autônomas tornou as lutas pelo reconhecimento de demandas identitárias mais notáveis. É justamente perante esse processo de assimilação de novos atores que diversos estudos críticos (BENHABIB, 1992; FRASER, 1997; YOUNG, 1990, 1997; DRYZEK, 2002) apontaram as dificuldades e limitações do modelo liberal da democracia em lidar com as novas demandas por reconhecimento nas esferas públicas, particularmente dadas as afirmações liberais que enfatizam, sobretudo, as questões de legitimidade, de poder e de racionalidade.

Sendo assim, a teoria democrática viu-se em face de um problema: como incorporar mudanças que assinalariam uma ampliação dos espaços de participação? Observou-se que a teoria democrática passou por uma forte transformação ao posicionar-se a deliberação como forma de oposição às idéias de agregação e comportamento estratégico. Subjacente a essa mudança, há o objetivo, teórico e prático, de ampliar os espaços de participação, frente à diversidade e forte presença dos novos movimentos sociais, que incluem os movimentos por paz, movimentos ecológicos, os movimentos feministas e de mulheres, entre outros (BENHABIB, 1996; BOHMAN, 1998; DRYZEK, 2002). Nesse sentido, a deliberação consiste em um processo distinto de comunicação em que sujeitos têm a oportunidade de mudar as suas opiniões, preferências e/ou pontos de vista durante um processo interativo que envolve persuasão em vez de coerção, manipulação ou engano (DRYZEK, 2002, p.1). 
Os próprios deliberacionistas têm contribuído com suas reflexões e críticas acerca do melhor caminho para a teoria deliberativa. Uma das críticas a este modelo teórico diz respeito ao uso da racionalidade como única forma de argumentação e de ação e seus limites para lidar com a questão da inclusão. Diante da centralidade dessa preocupação, o artigo apresenta as discussões feitas por Iris Young $(1990,1997,2001)$ e por Paul Hoggett e Simon Thompson (2002). Além de concentrar na crítica ao uso da racionalidade no processo deliberativo, busca-se enfatizar a necessidade dos estudos sobre democracia deliberativa retomarem os objetivos oriundos da teoria crítica ou, em outras palavras, insiste-se que tais estudos devem servir para desvelar padrões enraizados de dominação que visam a manter o interesse e poder de certos grupos em detrimento de outros grupos e subjetividades coletivas. Desse modo, as discussões apresentadas aqui partem dos debates existentes no interior da própria tradição da democracia deliberativa. O resultado é uma tentativa de oferecer uma pequena contribuição para tais reflexões críticas e avançar quanto às perguntas relacionadas ao processo de como tornar os espaços públicos de deliberação mais inclusivos.

A primeira parte deste trabalho apresenta uma breve discussão acerca da relevância do papel da esfera pública e dos potenciais da democracia deliberativa. A segunda parte do trabalho busca mapear as críticas ${ }^{2}$ à democracia deliberativa feitas por Young $(1990,1997$,

2 Está além do alcance desse artigo abordar o debate entre teóricos vinculados à Teoria da Escolha Racional e os deliberacionistas. Apesar disso, é importante destacar algumas das preocupações mais comumente dirigidas pela primeira tradição ao processo deliberativo. Segundo Przeworski (1998), o problema central da deliberação é que ela pode causar 'dominação ideológica'. Com essa argumentação, o autor busca enfatizar como as desigualdades sempre presentes em tais processos criam circunstâncias de manipulação e coerção, particularmente no que tange à produção de ideias acerca de experiências. Stokes (1998) é outra autora que apresenta três 'patologias' referentes ao processo deliberativo: (1) sua capacidade de reforçar o(s) interesse(s) do(s) comunicador(es), (2) o pensamento errôneo de que preferências mudam, e (3) que o processo em contextos desiguais pode ser capaz de reduzir o sentido que um indivíduo tem a respeito de suas capacidades (p. 124). Embora uma discussão acerca de cada problemática relacionada à teoria deliberativa não seja um dos objetivos desse trabalho, conforme já mencionado, vale ressaltar que Stokes (1998) apresenta sugestões, ou regras para deliberação, relevantes para evitar tanto as patologias apontadas e quanto o enraizamento de desigualdades mais profundas. 
2001) acerca da (1) questão da imparcialidade do público e (2) dos limites de se fundar toda a base de argumentação e ação no conceito de racionalidade. Já a terceira parte apresenta alternativas ao modelo racional de argumentação, presentes nas propostas de Young (1997) a respeito de "democracia comunicativa" e de Hoggett e Thompson (2002) no que se refere ao papel das emoções na deliberação.

Desse modo, fundamentado em críticas feministas, o artigo tem duas dimensões interligadas. Primeiramente, procura-se abordar as críticas ao uso da racionalidade ou "abstração de emoções" a fim de ilustrar como tal forma de argumentação cria certos limites para o processo deliberativo. Em segundo lugar, e partindo das discussões estabelecidas pelo primeiro objetivo, busca-se ilustrar como tal forma de comunicação está entrelaçada ao problema da inclusão por (1) não legitimar outras formas de comunicação e (2) reforçar diversos binarismos que trabalham por meio da exclusão. A propositura de novos elementos de argumentação aponta para a necessidade de se reexaminar e explicitar as formas e padrões de comunicação que perpetuam processos de exclusão e/ou subordinação no contexto de múltiplas subjetividades em sociedades modernas e complexas.

\section{Breves considerações acerca da esfera pública e os potenciais da democracia deliberativa}

Segundo Habermas (1962), a transformação estrutural da esfera pública ocorreu a partir das transformações operadas tanto no Estado quanto na economia. A esfera pública passou a ser concebida como um espaço onde indivíduos livres e privados, particularmente a classe media, reúnem-se para participar de um debate racional e criticamente orientado (HABERMAS, 1991). Com esta divisão, a esfera pública assumiu uma função política, viabilizando a participação dos cidadãos em um espaço informal capaz de influenciar o sistema político. A contribuição habermasiana para a teoria democrática estende-se além em um sentido duplo. Em primeiro lugar, a teoria da ação comunicativa desenvolve uma concepção de racionalidade cujo cerne é a própria argumentação, buscando, sobretudo, um entendimento mútuo entre os sujeitos participantes do debate público. Diante dessa abordagem teórica que informará as práticas 
intersubjetivas, a razão para Habermas não é, apenas, instrumental. Em segundo lugar, ela oferece um novo ponto de partida para a teoria crítica. Aqui, argumentações são capazes de destacar "de que modo interesses enraizados e institucionalizados na sociedade podem neutralizar e ofuscar o potencial de debate político capaz de revelar as injustiças (ANDERSON, 2000, p. 4).

A centralidade da teoria do discurso de Habermas (1996) reside no fato de que ela vai além tanto do modelo liberal quanto do modelo republicano no que tange sua tentativa de estabelecer a esfera pública como um lugar capaz de legitimar a opinião pública e as vontades coletivas. Por isso, e especialmente porque tal teoria visa o estabelecimento de um processo de comunicação intersubjetivo, possibilitando o caminho para o entendimento com o outro por meio das justificações dadas no discurso, os deliberacionistas têm bebido na fonte habermasiana para formular suas próprias teorias. O que se pode notar é que a democracia deliberativa vem sendo tratada com diversos vieses, ora enfatizando-se a questão do processo de deliberação em si, ora o processo de institucionalização, ora os procedimentos de deliberação que possam elucidar problemas empíricos (BOHMAN, 1998, p. 401) 3. Se, de um lado, pode-se traçar uma raiz liberal advinda da democracia deliberativa, por outro lado, pode-se traçar sua raiz oriunda da teoria crítica. A democracia deliberativa afirma a necessidade de se justificarem, em público, as decisões tomadas por cidadãos, e as razões utilizadas na formulação dessas justificativas devem apelar para os princípios de cooperação. Para além do ideal do consenso, a democracia deliberativa apresentouse como uma tentativa de recapturar a vontade dos cidadãos, por meio da sua deliberação pública (BOHMAN, 1998, p. 401).

Amy Gutmann e Dennis Thompson (2004, p. 3-7) iniciam a discussão sobre democracia deliberativa "afirmando a necessidade

3 No seu texto Survey Article: The Coming of Age of Deliberative Democracy (1998), James Bohman busca ilustrar essas três diferentes maneiras com que democracia deliberativa tem mudado.Já John Dryzek (2002) faz uma crítica pertinente a essas mudanças, ilustrando que a maturidade que Bohman aponta na democracia deliberativa, na verdade, não é um distanciamento forte e crítico do modelo liberal. Para Dryzek, o constitucionalismo liberal sempre esteve presente na teoria da democracia deliberativa, inclusive sua formulação inicial (2002, p. 28). 
de justificar as decisões tomadas tanto por cidadãos quanto por seus representantes". O processo de tomada de decisões baseado em razões deve cumprir quatro objetivos principais da democracia deliberativa: (1) o processo necessita do componente de decisões formadas e baseadas na razão; (2) as razões dadas, ao longo do processo, devem ser acessíveis a todos os cidadãos; (3) o processo visa a produzir uma decisão que seja vinculante e (4) o processo deve ser dinâmico. Uma das principais vantagens do modelo da teoria deliberativa em relação ao modelo agregativo é que, ao negar a condição de que as preferências são dadas, há um espaço para a colocação de novas preferências que, por sua vez, podem desafiar estruturas e barreiras de poder estabelecidas. Porém, é necessário perguntar se, de fato, o processo deliberativo é capaz de reverter certas distribuições de poder, quando temos grupos que historicamente foram dele excluídos.

Partindo das três primeiras características atribuídas à democracia deliberativa por Gutmann e Thompson (2004), a pergunta que norteia esse trabalho é: quão democráticos são os espaços e os momentos de deliberação? Em outras palavras, a promessa da democracia deliberativa de proporcionar um processo de tomada de decisões legitimado e baseado nos princípios de inclusão e igualdade é fundada? Desse modo, enfoca-se no trabalho a questão do processo deliberativo e os padrões de comunicação que possam viabilizar uma maior participação e inclusão dos cidadãos. Inevitavelmente, uma preocupação subjacente é investigar se a linguagem dos processos deliberativos é ampla o suficiente para ser compatível com a condição estabelecida por pressupostos da democracia deliberativa, mais especificamente o de criar um processo de respeito mútuo. Considerarei o processo deliberativo sob a ótica expressiva e não instrumental; a saber, a partir do entendimento de que o processo de deliberação está carregado de valores e significâncias vinculadas às pessoas que tomam a decisão (GUTMANN e THOMPSON, 2004) ${ }^{4}$. Trata-se de afastar a imagem do espaço público como um lugar de

4 Apesar de não entrar na discussão sobre as questões acerca dos procedimentos e substância para a democracia deliberativa, toma-se a posição de que teorias de democracia deliberativa devem compor princípios substantivos e procedimentais. 
disputas de poder, no qual ideias e opiniões competem entre si. A teoria discursiva carrega consigo uma miríade de possibilidades de trocas de valores, experiências e práticas, abrindo o terreno para não somente refletir sobre diferenças, mas também para democratizar esses espaços. Isso será possível por meio de uma postura que corresponda a certas iniciativas que contam, sobretudo, com o interesse e vontade dos cidadãos:

Parte dessa transformação pode acontecer por meio da abertura de oportunidades à participação, pela inclusão de vozes excluídas, pela democratização de acesso à mídia, pelo estabelecimento de 'reuniões de bairro', pela politização do que está despolitizado, pelo empoderamento dos desempoderados, pela descentralização da tomada de decisão, pela criação de comissões públicas para investigar a opinião pública, e assim por diante (CHAMBERS, 1995, p. 247).

Além disso, é importante ressaltar que a capacidade de transformação do modelo deliberativo depende da participação dos cidadãos em espaços informais bem como em formais. A ampliação dos espaços deliberativos serve para fortalecer a sociedade civil, aproximar os cidadãos do processo deliberativo e prepará-los melhor para tais processos (GUTMANN e THOMPSON, 2004, p. 35). O grande desafio da democracia deliberativa é buscar uma conexão entre a teoria e a prática, proporcionando um espaço para a revisão das normas que orientam as práticas. Com esses desafios em mente, os argumentos apresentados aqui buscam examinar certos pressupostos da deliberação com o intuito, em primeiro lugar, de lançar luzes sobre as formas de se pensar acerca dos modos e padrões de comunicação envolvidos em tais processos, e, em segundo lugar, de entender as suas capacidades de focar na questão da inclusão.

\section{Diferença, imparcialidade e razão: desafios para o potencial emancipatório da democracia deliberativa}

A teoria do discurso de Habermas serviu como fonte de grande discussão das estruturas e normas que constituem o mundo 
político e social, apesar de não tratar da questão de gênero. Diversas críticas direcionadas à concepção habermasiana da esfera pública são oriundas da própria teoria política feminista. Como Dahlberg (2005) aponta, elas se encontram em dois campos: (1) as críticas pós-modernas que buscam alternativas em relação à concepção habermasiana, como os trabalhos de Jodi Dean, Jane Flax, Chantal Mouffe, Judith Squires, entre outras; e (2) as críticas que, partindo da concepção habermasiana, procuram ir além dela, adicionando-lhe elementos faltantes, como os trabalhos de Nancy Fraser, Iris Young, Seyla Benhabib, entre outras. $\mathrm{O}$ argumento desenvolvido ao longo desse trabalho alinha-se ao segundo campo das críticas e é baseado, desse modo, em uma perspectiva feminista.

Para as teóricas feministas, que visam a romper com as estruturas e normas que subordinam e até mesmo ofuscam a subordinação, dominação e opressão das mulheres (e, por sua vez, dos grupos minoritários), a teoria habermasiana oferece uma reflexão que problematiza as estruturas políticas e sociais da vida moderna e estabelece a possibilidade do sujeito insurgir-se, através do discurso público, contra os padrões políticos de discurso já estabelecidos. Segundo tais autoras, Habermas reconhece que o discurso implica em um processo de mútuo reconhecimento, entretanto, ele não considera o importante fato de que há diversos obstáculos decorrentes da institucionalização de certas normas, principalmente em espaços formais. Diante de uma perspectiva feminista, pode-se perguntar se a concepção de esfera pública realmente leva em conta a diferença, sobretudo as diversas opiniões que surgem durante a deliberação. $\mathrm{E}$ se, realmente, esses espaços de diálogo e deliberação podem servir como um espaço emancipatório. Deve-se, então, discutir como enfrentar e reconhecer padrões de injustiça e exclusão que remetem a uma ordem de dominação cultural que significa, não exclusivamente, estar sujeito(a) a padrões de interpretação e comunicação.

Perante essas perguntas, Iris Young baseia seus argumentos em uma crítica feminista e emancipatória, cujo objetivo é ilustrar como os ideais normativos da tradicional teoria moral serviram e servem para reforçar dicotomias, como o público/privado e razão/ emoção. Esse enquadramento pretende justamente apontar para como tais oposições, fundadas em uma concepção do público im- 
pessoal e imparcial ${ }^{5}$, são incapazes de desafiar práticas de exclusão, mesmo tendo a aparente presença de grupos e/ou indivíduos historicamente excluídos nos espaços públicos (YOUNG, 1990). Young não foi a primeira a apontar as limitações do modelo liberal do espaço público e da separação do público/privado. Na verdade, a crítica à referida dicotomia configurou-se e configura grande premissa das discussões feministas. Cabe salientar que Seyla Benhabib (1992) já criticava o fato de o modelo liberal ter dois limites significativos. Primeiramente, para a autora, um limite do modelo liberal é pressupor que um diálogo seja neutro, admitindo que os grupos envolvidos não tenham uma opinião formada sobre o problema em questão. A segunda limitação é que o modelo oferece uma visão muito estreita e limitada da própria esfera pública, vendo-a como o espaço público inserido não na sociedade civil, mas no Estado ou mesmo nas instituições legais. A incorporação dos elementos de deliberação na esfera pública é essencial para fortalecer a vida pública-política, que visa a um bem comum alcançável pelo diálogo e não pela agregação de interesses.

Cabe destacar que Young (1990) afirma que Habermas foi mais além do que outros pensadores contemporâneos, ao elaborar um projeto de razão moral que reconhece a pluralidade dos sujeitos, mas não abriu mão de uma razão normativa que norteia a busca por uma compreensão discursiva que possa finalizar em consenso ( $\mathrm{p}$. 106-107). Essas críticas servem para fortalecer a tese de Young de que o ideal de uma razão moral corresponde a um ideal de público universal que, ao privilegiar um caráter mais racional e imparcial, exclui particularidades, desejos, sentimentos e todos os aspectos associados com o corpo (1990, p. 107). Essa exclusão do corpo e do sentimento implica na exclusão, principalmente, das mulheres e demais grupos étnicos e/ou minoritários. De acordo com Young,

5 A imparcialidade kantiana é, por excelência, a chave para a razão moral que, dentro da filosofia, fortaleceu e reforçou a separação da razão do desejo. Como dito anteriormente, teóricas feministas vêm mostrando como as mulheres têm sidas enquadradas dentro do estereótipo da emoção em contraposição à ideia de que os homens estariam responsáveis pelo cálculo da razão. Logo, as mulheres foram filosófica e racionalmente excluídas da possibilidade de racionalidade moral. Além de Young (1990), outras autoras lidam particularmente com essa dicotomização na filosofia ocidental, veja Lloyd (1993) e Schott (1988). 
o que é desejável nesses processos deliberativos opõe-se diretamente a formas de interação e comunicação que se baseiam em particularidades, afetividade e no uso do corpo. Isso é claramente exemplificado na sua afirmação de que "o homem respeitável deve ser heterossexual, desapaixonado, vinculado às regras. Os aspectos corporais, sexuais, incertos e desordenados da existência nessas imagens culturais foram e são identificados com as mulheres, homossexuais, negros, indianos, judeus e orientais" (1990, p. 111).

Um dos argumentos centrais de Young é a afirmação da questão da diferença, escapando da tendência, perante a lógica da identidade, de controlar a heterogeneidade. Essa diferença é dada em um espaço configurado por fluxos de experiências e significâncias que não devem ser subjugados a um processo de unificação. A diferença é uma parte intrínseca do próprio conceito de discurso, pois diante da pluralidade e heterogeneidade dos contextos, nenhuma palavra terá significado se ela não estiver diante um pano de fundo que a diferencie (YOUNG, 1990, p. 98). Os desafios à ideia de diferença são numerosos, particularmente quando pensamos na lógica da identidade que construiu estruturas de oposições binárias - como sujeito/objeto, mente/corpo, razão/emoção, homem/mulher, público/ privado e assim por diante - que compõem a história do pensamento filosófico ocidental. A lógica da identidade, a qual Young critica fortemente, busca reduzir tudo a um princípio, capaz de eliminar as possibilidades de incerteza e imprevisibilidade (YOUNG, 1990, p. 98-99). A saber, significa reduzir a heterogeneidade ou pluralidade dos sujeitos a um único modo de agir e pensar: o da razão universal. De acordo com Young, o problema dessa busca por unidade reside no fato de que ela apenas intensifica as dicotomias, transformando o diferente em o "outro". Nesse processo, há de fato uma oposição hierárquica, privilegiando-se a criação de uma esfera pública homogênea, orientada por uma lógica masculina.

Um sujeito que age diante de padrões de razão é, de fato, um sujeito que abstrai do processo de pensamento tudo aquilo associado com sentimentos e particularidades. De acordo com Young, isso torna o processo de pensamento não apenas um processo racional, mas imparcial, criando três obstáculos para o florescimento da diferença. Primeiramente, essa busca por uma razão universal esvazia 
as circunstâncias de qualquer tipo de particularidade. O sujeito é obrigado a tomar uma posição de raciocínio guiado por um ponto de vista constituído por princípios universais. Em segundo lugar, o conceito de imparcialidade trabalha com a tentativa de eliminar a heterogeneidade através do controle dos sentimentos, um dos pontos chaves da discussão feita por Hoggett e Thompson (2002). Isso constrói uma circunstância na qual a razão se opõe às experiências de vida e às particularidades que possam conter qualquer resquício de afetividade e emoção. Desse modo, essas particularidades que formam um sujeito diferente são, de fato, eliminadas ou no mínimo ofuscadas. E, finalmente, a terceira e mais forte maneira pela qual a imparcialidade reduz a particularidade é através do processo de minimização da pluralidade dos sujeitos a uma única subjetividade (YOUNG, 1990, p. 100). Dentro de uma perspectiva universalista, o conceito de razão visa a estabelecer um ponto de partida que todos os sujeitos racionais possam adotar, novamente reduzindo as suas particularidades. $O$ resultado final dessa busca não é o alcance de certa unidade, já que as diferenças, sentimentos, inclinações e necessidades não podem ser completamente retirados do sujeito. Na verdade, o que ocorre é uma forte dicotomização do público e privado, sendo o público o lugar da razão formal.

Interessante perceber que a legitimidade do espaço público como o lugar da racionalidade conseguiu excluir sujeitos que não se encaixavam nos moldes desse certo tipo de ação, além de eliminar qualquer tipo de discurso que remetesse a outros padrões. Joan Landes (1988) oferece mais uma crítica relevante sobre a exclusão das mulheres na conceituação da esfera pública. Para Landes, a criação desse novo espaço público formou-se como oposição deliberada à cultura de salões, que era mais aberta à participação das mulheres. Por sua vez, os salões tiveram uma caracterização de "artificiais," "efeminados," e "aristocráticos," enquanto uma nova forma de discurso público foi promovida, caracterizada como "racional," "virtuosa," e "masculina" (FRASER, 1997, p. 73). Tudo aponta para o fato de que a formação desse espaço público burguês misturava elementos diferentes de discurso. Young ressalta que essa mistura não sobreviveu e suprimiu-se a linguagem heterogênea e popular (1990, p. 108), criando-se um padrão de sociabilidade ancorado na racionalidade. 
Por isso, serviu apenas para enrijecer a separação do público e do privado. Essa divisão é ilustrativa das relações de gênero que ainda hoje estruturam a dinâmica do poder nos dois âmbitos, institucionalizando padrões aceitáveis e naturalizados de androcentrismo.

Expressamente codificados em muitas áreas do direito (incluindo o direito de família e o direito penal), eles informam as construções legais de privacidade, autonomia, autodefesa e igualdade. Eles também estão embutidos em muitas áreas da política governamental (incluindo política reprodutiva, de imigração e de asilo) e em práticas profissionais padrão (incluindo medicina e psicoterapia). Padrões androcêntricos de valoração também permeiam a cultura popular e a interação cotidiana. Como um resultado, as mulheres sofrem formas específicas de gênero de subordinação de status, incluindo violação e violência doméstica; representações estereotipadas trivializantes, objetificantes e humilhantes nos meios de comunicação; assédio e depreciação na vida cotidiana; exclusão ou marginalização nas esferas públicas ou nos corpos deliberativos; e negação de direito integral e proteções iguais decorrentes da cidadania (FRASER, 2003, p.21).

As críticas feministas à esfera pública representaram grandes contribuições para a teoria política ao apontar que a construção da esfera pública excluiu e desempoderou as mulheres por relegaremnas à esfera da domesticidade. Mais importante, ainda, é o fato de as críticas feministas reconhecerem que o processo de socialização, que percorre todos os âmbitos da vida, instala valores e crenças que colocam as mulheres em posições inferiores, criando uma aceitação desses valores desiguais não somente pelos homens, mas pelas próprias mulheres.

Além das feministas, os teóricos do reconhecimento forneceram importantes contribuições para a problematização da esfera pública. Dentre eles, pode-se apontar Charles Taylor (1989), cujas ideais servem como uma importante ferramenta de análise das questões sobre o reconhecimento, a internalização de crenças, valores e estereótipos que subordinam certos grupos, e a necessidade de deliberação e debate que inclua todos os membros da sociedade, respeitando, sobretudo, as diversas maneiras de agir e pensar. A internalização de crenças, via um processo de reconhecimento ou 
não-reconhecimento, interfere na conscientização que um sujeito possa ter em relação a um conhecimento mais completo de si e, até mesmo, pode impedir a criação de espaços dialógicos onde indivíduos se sintam protegidos para expressar suas opiniões e sentimentos. Consequientemente, quando não reconhecemos um outro ser estamos negando a sua possibilidade de autoafirmação e, eu acrescentaria, o seu desejo de articular suas necessidades, experiências de vida e sentimentos:

Nossa identidade é parcialmente moldada pelo reconhecimento ou por sua ausência, frequientemente pelo falso reconhecimento dos outros, e assim uma pessoa ou um grupo de pessoas pode sofrer verdadeiro dano, verdadeira distorção, se as pessoas ou a sociedade ao redor refletem-lhe uma imagem limitada, humilhante ou desprezível dele mesmo. $\mathrm{O}$ não reconhecimento ou o falso reconhecimento pode infligir dano, pode ser uma forma de opressão, aprisionando alguém em um modo de ser falso, distorcido e reduzido (TAYLOR, 1989, p. 25).

Qual é a relevância das discussões centradas na teoria do reconhecimento para as questões envolvendo as criticas de deliberação? A resposta aqui é dupla. Primeiramente, é preciso considerar reconhecimento, em si, como uma questão de status e não apenas como uma forma de alcançar uma autoestima completa ${ }^{6}$ (FRASER, 2001, 2003). Mais particularmente, como Fraser afirma, alinhando reconhecimento como uma forma de lidar com injustiças e não meramente autorrealização, conseguimos destacar os tipos de interação que valorizam certos padrões culturais e simbólicos como sendo superiores a outros (2003, p. 29). Quando padrões interativos desvalorizam e atribuem um status inferior a certos indivíduos ou grupos, baseados em raça, sexo, etnia, sexualidade, dentre outros, existe uma clara implicação na maneira como esses indivíduos ou grupos participam da vida social. Em ultima instância, o não-reconhecimento, ou como Fraser designa, subordinação de status, representa as maneiras como tais indivíduos ou grupos são impedidos de participar como pares em diversos modos e espaços de interação.

6 Para o debate no que concerne ao potencial do reconhecimento, dentro da perspectiva da teoria crítica, veja FRASER e HONNETH (2003). 
Dada essa contextualização, alinham-se aqui padrões de interação e comunicação, governados pelo princípio da racionalidade, como uma forma específica de negar a um sujeito sua capacidade de participar plenamente como um par na(s) esfera(s) pública(s). Em segundo lugar, a questão do reconhecimento é relevante para as teorias de deliberação porque está ligada às questões maiores da teoria democrática: como tornar a(s) esfera(s) pública(s) lugares mais igualitários, capazes de integrar as pluralidades das sociedades contemporâneas.

Como havia sido apontado anteriormente, a discussão sobre a dicotomia das esferas pública/privada é bastante cara às feministas, justamente pelo fato de que as dinâmicas das relações nas esferas não podem ser entendidas separadamente. Ao enfatizar essa divisão, pode-se ilustrar como os espaços de socialização e diálogo excluíram as mulheres, criando empecilhos profundos para a sua efetiva participação nos diversos espaços da sociedade. Pesquisas feministas ${ }^{7}$ documentaram as dinâmicas que ocorrem em espaços de deliberação entre mulheres e homens. Muitas vezes, o que acontece é que os homens interrompem mais as mulheres, os homens falam mais do que as mulheres e quando as mulheres finalmente podem falar, elas são ignoradas (FRASER, 1997). Essa exclusão deve ser estendida para outros grupos identitários também. Cabe ressaltar que muitas vezes a exclusão de mulheres nas esferas públicas não é de forma totalizante; o que se encontra, portanto, são condições menos favoráveis de se fazerem audíveis. Para a feminista Carole Pateman (1985), dado o fato de que "mulheres encontram seus padrões de fala (speech) persistente e sistematicamente invalidados", isto teria sérias implicações no que concerne aos aspectos de debate, um conceito fundamental para democracia. Outra forma de abordar tal questão é proposta por Mansbridge (citada por HALL, ano) que chama atenção para o fato de que o problema da separação histórica e filosófica entre razão e emoção/desejo, não é necessariamente o fato de as mulheres serem excluídas, mas que a comunicação fundada em emoções, em si, não tem sido reconhecida ou legitimada.

7 Para uma discussão mais ampla, veja Fraser (1997) citando as pesquisas de Jane Mansbridge. 
Desse modo, a preocupação maior é como subverter os moldes de interação em estruturas que perpetuam a dominação e subordinação das mulheres e, consequientemente, grupos minoritários e/ou identitários que não se ajustam ao padrão racional.

\section{Rompendo a dicotomia razão/emoção: os potenciais de novos padrões comunicativos}

Se, de fato, buscamos revitalizar o processo deliberativo, é necessário romper com os moldes de racionalidade, neutralidade e imparcialidade discutidos nas seções anteriores e ampliar os espaços de deliberação. Existe uma clara necessidade de demolir as estruturas hierárquicas que privilegiaram os espaços públicos dominados por homens brancos, heterossexuais, de classe média/ alta. Até mesmo com o crescimento e surgimento dos novos espaços de debate, ou múltiplos públicos, a questão não-resolvida é como legitimar e ampliar esses espaços para grupos e identidades excluídos ou ignorados até então. É preciso repensar os modos de fala que incluem aspectos essenciais, tais como elementos dramáticos e metafóricos da fala, gestos, expressões faciais, tonalidade de voz para, efetivamente, chegar a uma compreensão da experiência de certo grupo. Partindo desses exemplos, Young 8 (1997) propõe ir além da democracia deliberativa, reivindicando uma teoria e prática mais abrangentes e inclusivas: a democracia comunicativa.

Para Iris Young (1990, 1997a), Nancy Fraser (1986, 1997, 2003) e John Dryzek (2002), existe uma tensão nas teorias políticas modernas incapazes de reestruturar e/ou radicalizar os modelos postos da democracia e da própria deliberação. Existe uma clara necessidade de estabelecer a igualdade, em seus vários níveis e patamares, de modo que todos os indivíduos gozem dos mesmos direitos e de igual reconhecimento.

Young, em seu texto clássico Communication and the Other: Beyond Deliberative Democracy (1997a), sustenta um modelo de co-

8 Para outras feministas que discutem os modos de comunicação apresentados por Young mas por meio de uma abordagem que não se enquadra dentro da democracia comunicativa proposta por ela, veja HALL (2007) e DREXLER (2007). 
municação que incorpora novos elementos no processo discursivo, como cumprimentos (greetings), retórica (rhetoric), e contos ou narrativas (storytelling). $\mathrm{O}$ modelo de democracia deliberativa trabalha com o pressuposto de que os cidadãos buscam, nos espaços públicos, uma troca de argumentos, opiniões e ideias, reconhecendo a possibilidade de mudar as próprias opiniões. O objetivo maior de Young, e mais brevemente de Hoggett e Thompson (2002), é ampliar esse espaço para que o processo deliberativo não caia na armadilha de modos de interação guiados apenas pela rigidez, objetividade e falta de expressão emocional. A proposta da democracia comunicativa pretende ir além da democracia deliberativa, por entender que um diálogo não está interessado apenas em chegar a uma decisão coletiva, mas em incluir, no processo, diversos estilos de fala e ação que remetam à pluralidade e diversidade dos seus integrantes. Apesar da autora não desenvolver e/ou elaborar profundamente as três dimensões que o diálogo deveria incorporar, ela assinala problemas por acreditar que certos sujeitos não têm a mesma voz e valor no espaço público. Isso é um importante fator quando se considera que, de fato, a inclusão de diversas formas e estilos de linguagem é capaz de ampliar os espaços de deliberação e estabelecer condições paritárias para participação.

O primeiro modo de comunicação que Young (1997a) apresenta é o conceito de cumprimento (greetings). Para manter uma condição de diálogo que almeja um ponto de compreensão, é importante estabelecer as particularidades do outro. Nesse primeiro momento do diálogo, Young aceita que não há, de fato, qualquer pretensão de estabelecer um argumento ou afirmação concreta. O que ele representa mesmo é um momento de instituir certo respeito e confiança entre os interlocutores, introduzindo elementos de corporalidade, que incluem gestos de polidez e respeito como um sorriso, aperto de mão e/ou um abraço, nesse ideal de democracia comunicativa. Para Dahlberg (2005), que não somente examina os três modos de comunicação discutidos por Young, mas defende a concepção habermasiana da esfera pública como sendo capaz de maximizar a inclusão da diferença na troca deliberativa, o cumprimento serve como um complemento para as deliberações, particularmente quando fortes contestações estão em jogo. 
O segundo elemento, a retórica, busca situar o processo comunicativo, estabelecendo claramente a relação entre o orador e sua audiência e, ao mesmo tempo, construindo a ocasião da comunicação (YOUNG, 1997a, p. 71). Dos três elementos comunicativos que Young aponta, enfatiza-se o elemento de retórica, pois nela pode-se notar uma potencialidade política de abertura para uma maior e igual participação. Esta abertura pode vir a desafiar as regras do jogo na esfera pública, que refletem formas patriarcais de agir, de falar e, enfim, de participar, por meio de uma nova dinâmica, construindo significados, conotações e símbolos (YOUNG, 1997a, p. 71). Entende-se o instrumento da retórica como uma forma de escapar das normas preestabelecidas no processo deliberativo que privilegiam a racionalidade, em detrimento de outros estilos e padrões de comunicação. A retórica é, muitas vezes, vista como um elemento negativo dentro da perspectiva da democracia deliberativa, devido ao apelo à emoção (DRYZEK, 2002) ${ }^{9}$.

Entretanto, o potencial da retórica reside no fato de que ela incorpora emoções a fim de alcançar uma audiência específica, sobretudo, mantendo sua atenção. Cabe salientar que o elemento de retórica, idealmente, deve incluir também uma certa racionalidade, que possa estar por trás da tentativa de adesão do público em questão. O que se encontra é uma maneira de trazer, para o público, questões privadas ou pessoais de certos grupos, i.e, suas particularidades ou experiências de vida, que buscam persuadir a partir da localização de sua identidade. Nesse mesmo sentido, Dahlberg (2005) acredita no potencial da retórica no sentido de que, ao longo da historia, tal forma de comunicação se configurou como forma de protesto civil, como no caso dos negros reivindicando seus direitos civis nos Estados Unidos durante os anos 60 ou o movimento sufragista no Canadá.

$O$ terceiro elemento refere-se à forma narrativa de comunicação que Young (1997a) designa de storytelling. A narrativa é

9 Seria ingênuo não levar em consideração críticas ao uso da retórica que enfatizam as maneiras em que ela pode ser usada para dominar e excluir, apontadas pelo próprio Habermas (1991) em Mudança Estrutural da Esfera Pública e por vários outros. 
importante durante o diálogo, pois ilustra as particularidades dos indivíduos sem remontar a um processo de simetria ${ }^{10}$. A narrativa pode criar momentos de afinidade entre os sujeitos, ao mesmo tempo em que afirma as suas diferenças. Talvez um dos elementos mais significativos da narrativa seja sua capacidade de transmitir não somente a experiência subjetiva, mas também valores, cultura e conhecimento específico. Esse conhecimento pode transformar e contribuir para um argumento político que incorpora o contexto de vida do sujeito que narra (YOUNG, 1997a). As narrativas contribuem para o processo deliberativo por sua capacidade de ilustrar como certas injustiças afetam grupos distintos, exemplos disso são o uso dessa forma de comunicação em relatos de assédio sexual ou em narrativas de escravos (DAHLBERG, 2005, p. 118).

O uso desses estilos de linguagem possibilita a expressão e a identificação de diferenças sociais. Isso não garante que problemas com o entendimento e o respeito mútuo não ocorram. O que é necessário é buscar entender o lugar do outro e, aí sim, encontrar momentos de experiências de vida que se aproximem ou não. $\mathrm{O}$ que não pode haver, portanto, é uma falsa projeção que sustente a idéia de que há igualdade em um contexto de diferença.

Então, o que estes modos de comunicação têm em relação à questão do potencial transformativo de uma teoria de deliberação? Primeiramente, esses modos permitem às pessoas falarem em suas próprias vozes. Em segundo lugar, eles estão ligados com outra crítica à democracia deliberativa, feita por Young: os modos de agir. Para Young (2001), a democracia deliberativa reforça práticas de diálogo que refletem formas de argumentação racional e que não remetem a qualquer tipo de força ou ameaça. Novamente, Young

10 Young faz uma discussão pertinente sobre a questão da assimetria recíproca durante o processo de diálogo. Ao contrário de Benhabib, que afirma que o respeito mútuo é uma relação simétrica, Young acredita que é impossível adotar essa posição já que a simetria depende de uma pessoa acreditar que ele/ela possa se ver refletido no outro. Para Young, essa projeção é falsa pois não há forma de se reverter a posição de um indivíduo, particularmente dado o fato de que sempre há uma questão de privilegio e opressão nas relações sociais (1997b, p. 347). O maior perigo nesse processo de falsa projeção é que certos estereótipos e ideologias imbricados nas relações possam se tornar legítimos. 
busca romper com formas tradicionais de falar e agir, desafiando a democracia deliberativa ao pensar nas estruturas e instituições que perpetuam injustiças, pois são nesses espaços que o processo deliberativo frequientemente ocorre (ou não). A leitura que se faz dessa crítica de Young é muito próxima das reflexões acerca dos padrões comunicativos: existe uma urgência em criar outras formas de falar e agir que demonstram, sobretudo, uma atividade crítica e de oposição ao processo racional (2001, p. 671). Além disso, a democracia deliberativa deve tomar uma posição mais radical que rompa com as estruturas hierarquizadas e institucionalizadas de poder.

É partindo dessa crítica que se pretende estender a discussão sobre a questão da argumentação racional na democracia deliberativa. Paul Hoggett e Simon Thompson, em Toward a Democracy of the Emotions (2002), partem dos mesmos pressupostos de Young (1997a, b) e arriscam-se a construir um novo conceito de democracia que inclui as emoções. A argumentação dos autores é ancorada nas críticas feministas sobre a racionalidade, a qual estrutura grande parte das normas da democracia deliberativa, e em perspectivas da psicanálise ${ }^{11}$ que unem razão e desejos (passions) nas práticas deliberativas. Mais uma vez, tem-se o objetivo de ampliar o conceito de deliberação, ressaltando o fato de que a razão, muitas vezes, não consegue se separar das emoções, por essas serem elementos constitutivos do processo reflexivo do diálogo e das dinâmicas das relações sociais. Pautados nesse entendimento, Hoggett e Thompson procuram demonstrar que a razão e o entendimento não são apenas um processo cognitivo, mas influenciados pelos sentimentos (2002, p. 114). Há uma inegável inter-relação entre o uso da emoção e o processo do entendimento que decorre, na prática, da deliberação como apontam Hoggett e Thompson:

Primeiro, conhecimento e paixão, pensamento e sentimento, são dimensões separadas mas interpenetrantes da experiência humana. Eles são co-presentes constantes da experiência humana: onde quer que haja experiência, haverá conhecimento e haverá paixão, interligados em muitas diferentes formas. Isso será muito

11 Hoggett e Thompson (2002) baseiam sua sofisticada discussão sobre a perspectiva da psicanálise principalmente nas obras de Melanie Klein e Wilfred Bion. 
relevante ao se considerar as formas como o eu entende - ou falha em entender - o outro. Segundo, nosso status de seres coletivos [...] significa que as emoções pertencem, no mínimo, ao grupo tanto quanto ao indivíduo. Se essas duas proposições são consideradas conjuntamente, sua pertinência para a democracia deliberativa será evidente. Qualquer grupo de pessoas envolvidas em processos de deliberação gerará uma dinâmica emocional. [...] Essa dinâmica influenciará e será influenciada por processos de entendimentos, desentendimentos, reflexão, persuasão, acordo e desacordo que constitui a deliberação (2002, p. 112, tradução da autora).

Parece claro que essas colocações pretendem lançar luz sobre a limitação da oposição binária razão x emoção. É um equívoco pensar que discursos políticos não estão agitados por sentimentos que incitam paixões, algo que não necessariamente faz parte da agenda de revolucionários ou militantes e sim de numerosos líderes políticos $^{12}$ (HOGGETT e THOMPSON, 2002, p. 113).

De acordo com Hoggett e Thompson, a teoria da democracia deliberativa retirou elementos de emoção de sua formulação para estabelecer condições de argumentação racional. Nessa tradição, as emoções são consideradas como uma "força desestabilizadora e perigosa" justamente por apelarem para a irracionalidade (HOGGETT e THOMPSON, 2002, p. 107). Os autores trazem uma contribuição ao apontarem, como Young em suas discussões sobre diferença e particularidade, que, ao fazer isso, a democracia deliberativa criou uma teoria política um tanto abstrata, racional e longe da realidade política contemporânea, já que sentimentos tais como medo, ódio, crueldade e até mesmo compaixão constituem os espaços públicos de deliberação.

Além de ser uma força construtiva, o afeto durante a deliberação pode ter seu potencial destrutivo. Hoggett e Thompson (2002), cientes desse potencial, ilustram essa capacidade com atas de reuniões públicas sobre moradia durante os anos 90 em Londres. As atas demonstram claramente sentimentos racistas em referência

12 Hoggett e Thompson apontam que a linguagem cheia de emoção é frequientemente usada por figuras políticas, tais como Thatcher, Clinton e Bush. 
à grande minoria de Bangladesh que morava nas áreas em questão. De fato, a linguagem carregada de emoções pode (1) minar os objetivos de uma deliberação, mesmo com o pré-estabelecimento de regras e (2) abrir o caminho para oportunistas políticos. Para Hoggett \& Thompson, é necessário incorporar nos momentos de deliberação diversos padrões de linguagem que, embora nem sempre estejam vinculados à razão, não destroem a qualidade da deliberação, colocando em risco o processo democrático (2002, p. 118). Uma vez que os processos deliberativos, querendo ou não, incorporam elementos de fortes emoções, ressaltando as particularidades dos sujeitos que participam, a teoria da democracia deliberativa deveria reconhecer dois aspectos intrínsecos ao processo comunicativo. Primeiro, que a razão deveria sempre ser entendida em relação à cognição e ao afeto, buscando claramente evitar a dicotomização da razão/emoção. Segundo, todo processo comunicativo está associado com algum traço de emoção. Hoggett e Thompson deixam clara sua preocupação em serem criticados por criar uma ontologia afetiva da racionalidade. Eles argumentam que seu objetivo é, portanto, oferecer uma forma mais ampla e rica de entender a racionalidade (2002, p. 123).

\section{Conclusão}

Este trabalho apresenta argumentos que não somente contestam as formas de interação e comunicação baseadas na racionalidade, mas também apontam para caminhos capazes de ampliarem o entendimento da própria noção de deliberação. Acredita-se que o desenvolvimento aqui proposto nos leva a duas conclusões básicas em relação às práticas deliberativas e ao estabelecimento de uma participação mais inclusiva nas esferas públicas. Em primeiro lugar, ao incorporar outras formas de ação e padrões comunicativos que não se submetem à ordem lógica e racional, teóricos da democracia deliberativa podem analisar, com um viés mais crítico, o quão justas e inclusivas suas praticas realmente são. Já que nem todas as interações são baseadas em argumentação racional, teóricos poderiam refletir mais criticamente sobre as normas que guiam as práticas e potencialmente revelar formas ocultas de dominação, dadas as 
estruturas desiguais que estão não somente enraizadas mas, frequientemente, legitimadas nas sociedades. Como se tentou mostrar, padrões comunicativos, baseados na racionalidade e imparcialidade, são interligados aos conceitos de poder que governam as regras, tanto das instituições econômicas e políticas quanto normas culturais. Estes padrões são importantes, pois eles influenciam formas de pensar e agir nas duas esferas: pública e privada. Isso levanta relevantes considerações acerca do papel exercido por certos sujeitos e/ou grupos em instâncias de deliberação, principalmente porque as estruturas de poder não podem ser simplesmente ignoradas. Por esta razão, o papel e o status designado para certos sujeitos pode muito bem afetar a habilidade de ser escutado e/ou compreendido em condições de paridade. De maneira alguma está se negando o fato de que é uma coisa falar de normas e ideais e outra coisa falar em prática. Contudo, se teóricos associados à democracia deliberativa buscam resgatar uma perspectiva mais crítica, é essencial reconsiderar e avaliar se tanto as normas teóricas quanto as práticas constituem as maneiras mais eficientes de garantir inclusão e superar padrões ocultos de dominação. Essa reflexão crítica poderá conduzir a um entendimento de que a legitimidade, hoje em dia, está inerentemente ligada a como as práticas democráticas lidam com a pluralidade. Em suma, a argumentação baseada na pluralidade pode gerar decisões mais qualificadas, resultando, por sua vez, na possibilidade de se integrar igualdade social, diversidade cultural e uma democracia mais participativa (FRASER, 1997, p. 85).

Em segundo lugar, essas reflexões ajudam a reforçar a premissa básica da democracia deliberativa: um espaço livre de trocas de ideias e opiniões. Também se ressalta que tal espaço deveria ser capaz de refletir a pluralidade por meio do reconhecimento. $O$ efeito combinado dessa livre troca de opiniões e do reconhecimento da pluralidade é o empoderamento de determinados grupos, anteriormente colocados em posições subordinadas, possibilitado através da linguagem. Em outras palavras, por meio de interações comunicativas, indivíduos e/ou grupos minoritários são garantidos a expressão e o reconhecimento das suas próprias vozes, levando em conta as regras necessárias para o estabelecimento da deliberação. 
Incorpora-se, portanto, o uso da esfera pública pelos sujeitos participantes do discurso para que possam criar sua própria história nos processos deliberativos e colocar em prática sua liberdade política através de ações espontâneas capazes de possibilitar inclusão ou até mesmo contestação da ordem estabelecida. É dentro desse eixo que se encontra um terreno rico para a reflexão sobre a dinâmica que ocorre na relação entre Estado e sociedade, bem como a assimilação e reconhecimento de novos atores historicamente excluídos. Evidentemente, essa reflexão corresponde não somente à busca por uma construção mais paritária e justa de democracia, mas também ilustra a relevância das lutas por reconhecimento, pois elas servem como um viés para contestarmos os valores institucionalizados de uma ordem que privilegia o masculino. Sustenta-se, portanto, que as lutas pelo reconhecimento estão fortemente ligadas às críticas apresentadas aqui, pois elas não somente apontam para obstáculos que impedem a inclusão, mas também se dirigem contra valores culturais sustentadores de padrões de interpretação e comunicação que perpetuam estruturas e práticas de subordinação e, portanto, exclusão.

Recebido em 2.9.2008 Aprovado em 18.9.2009

\section{Referências}

ANDERSON, Joel. "The Third Generation of the Frankfurt School". Intellectual History Newsletter 22, 2000. http://igitur-archive.library. uu.nl/ph/2007-0306-01415/anderson_01_thirdgeneration.pdf

ARENDT, Hannah. The human condition. 2. ed. Chicago: The University of Chicago Press, 1958.

AVRITZER, Leonardo e COSTA, Sérgio.Teoria Crítica, Democracia e Esfera Pública: Concepções e Usos na América Latina. Dados, v. 47, n. 4, p. 703-728, 2004.

BENHABIB, Seyla. The claims of culture. Princeton: Princeton University Press, 2002. 
. Toward a deliberative model of democratic legitimacy. In: BENHABIB, Seyla. Democracy and difference. Princeton: Princeton University Press, 1996, p. 67-94.

. Models of public space: Hannah Arendt, the liberal tradition, and Jurgen Habermas. In: CALHOUN, C. (Ed.) Habermas and the Public Sphere. Massachusetts: MIT, 1992, p. 73-98.

BOHMAN, James. Survey Article: The Coming of Age of Deliberative Democracy. The Journal of Political Philosophy, v. 6, n. 4, p.400-425, dezembro, 1998.

CHAMBERS, Simone. Discourse and democratic practices. In: WHITE, S. (Ed.) The Cambridge Companion to Habermas. Cambridge, Cambridge University Press, 1995, p. 233-259.

DAHLBERG, Lincoln. The Habermasian Public Sphere: Taking Difference Seriously? Theory and Society, v. 34, n. 2, p. 111-136, fall, 2005.

DREXLER, Jane. Politics Improper: Iris Marion Young, Hannah Arendt, and the Power of Performativity. Hypatia, v.22, n. 4, p. 1-15, fall, 2007.

DRYZEK, John. Deliberative Democracy and Beyond: Liberals, Critics, Contestations. 2. ed. Oxford, Oxford University Press, 2002, p.1-56.

FRASER, Nancy. Social justice in the age of identity politics: redistribution, recognition and participation. In: FRASER, Nancy; HONNETH, Axel. Redistribution or recognition? A politicalphilosophical exchange. 1. ed. London: Verso Press, 2003, p. 7-109.

. From redistribution to recognition? Dilemmas of justice in a 'postsocialist' age. In: FRASER, Nancy. Justice interruptus: critical reflections on the "postsocialist" condition. 1.ed. New York, London: Routledge, 1997, p. 11-39.

. What's Critical about Critical Theory: The Case of Habermas and Gender. In: BENHABIB, Seyla; CORNELL, Drucilla (Ed). Feminism as Critique. 2. ed. Minneapolis: University of Minnesota Press, 1986, p. 31-56.

GUTMAN, Amy e THOMPSON, Dennis. Why Deliberative Democracy? 1. ed. Princeton: Princeton University Press, 2004, p. 1-63. 
HABERMAS, Jürgen. The Structural Transformation of the Public Sphere: An Inquiry into a category of bourgeois society. 1. ed. Massachusetts, MIT Press, 1991.

. Deliberative Politics: A procedural concept of democracy. In: HABERMAS, Jürgen. Between Facts and Norms. Massachusetts, MIT Press, 1996, p. 287-328.

HOGGETT, Paul e THOMPSON, Simon. Toward a Democracy of the Emotions. Constellations, v. 9, n.1, p.106-126, 2002.

LANDES, Joan B. The Public and Private Sphere: A Feminist Reconsideration. In: MEEHAN, Johanna. (Ed). Feminists Read Habermas. NY: Routledge, 1988, p. 91-116.

LLOYD, Genevieve. The Man of Reason: "Male" and "Female" in Western Philosophy. 2. ed. London: Routledge, 1993.

PRZEWORSKI, Adam. Deliberation and Ideological Domination. In: ELSTER, Jon. (Ed.) Deliberative Democracy. Cambridge, Cambridge University Press, 1998, p. 140- 160.

SCHOTT, Robin May. Eros e os Processos Cognitivos: Uma critica da objetividade em filosofia. Rio de Janeiro, Editora Rosa dos Tempos, 1988.

STOKES, Susan. Pathologies of Deliberation. In: ELSTER, Jon. (Ed.) Deliberative Democracy. Cambridge, Cambridge University Press, 1998, p. 123- 139.

TAYLOR, Charles. Sources of the Self. Boston, Harvard University Press, 1989.

YOUNG, Iris. Activists Challenge Deliberative Democracy. Political Theory, v. 29, n. 2, p. 670-690, outubro, 2001.

Communication and the Other: Beyond Deliberative Democracy. In: YOUNG, Iris. Intersecting Voices. Princeton: Princeton University Press, 1997, p. 60-74.

. Assymetrical Reciprocity: On Moral Respect, Wonder, and Enlarged Thought. In: YOUNG, Iris. Intersecting Voices. Princeton: Princeton University Press, 1997, p. 38-59.

. The Impartiality of the Civic Public. In: YOUNG, Iris. Justice and the Politics of Difference. Princeton: Princeton University Press, 1990, p. 96-121. 


\begin{abstract}
Beyond rationality: in search of a broader view of the deliberative process

In light of the widening of contemporary struggles for recognition, within a context of greater visibility for new actors within public spaces, we have been able to identify the limitations of the liberal model of democracy which emphasizes, above all, legitimacy, power and rationality. This article proposes to take a look at the wide range of criticisms of deliberative democracy, particularly with regard to the use of rationality as the sole form of argumentation and action. Our critique of the use of rationality is anchored in Young's (1990, 1997, 2001) and Hoggett and Thompson's (2002) discussions. The incorporation of other forms of action and communicative patterns represents an attempt to make deliberative processes more inclusive, so that they may truly become sites of equality and emancipation.
\end{abstract}

Keywords: Deliberative democracy, rationality, inclusion. 